\title{
Phototherapy in dermatological maladies (Review)
}

\author{
DACIANA ELENA BRANISTEANU ${ }^{1 *}$, DIANA STEFANIA DIRZU ${ }^{2}$, MIHAELA PAULA TOADER $^{3 *}$, \\ DANIEL CONSTANTIN BRANISTEANU ${ }^{4 *}$, ALIN CODRUT NICOLESCU ${ }^{5}$, ILARIE BRIHAN $^{6}$, \\ CAMELIA MARGARETA BOGDANICI ${ }^{7}$, GEORGE BRANISTEANU ${ }^{8}$, ANDREEA DIMITRIU ${ }^{9}$, \\ NICOLETA ANTON ${ }^{10}$ and ELENA ANDRESE PORUMB ${ }^{11}$ \\ ${ }^{1}$ Department of Dermatology, 'Grigore T. Popa' University of Medicine and Pharmacy, 700115 Iasi; \\ ${ }^{2}$ Department of Dermatology, Railway Clinical Hospital, 700506 Iasi; Departments of ${ }^{3}$ Oral Dermatology and \\ ${ }^{4}$ Ophthalmology, 'Grigore T. Popa' University of Medicine and Pharmacy, 700115 Iasi; \\ ${ }^{5}$ Department of Dermatology, 'Roma' Medical Center for Diagnosis and Treatment, 011773 Bucharest; \\ ${ }^{6}$ Dermatology Department, Dermatology Clinic, Faculty of Medicine and Pharmacy, University of Oradea, 410073 Oradea; \\ ${ }^{7}$ Department of Ophthalmology; ${ }^{8}$ Faculty of Medicine, 'Grigore T. Popa' University of Medicine and Pharmacy, \\ 700115 Iasi; ${ }^{9}$ Department of Dermatology, 'Arcadia' Hospitals and Medical Centers, 700620 Iasi; \\ Departments of ${ }^{10}$ Ophthalmology and ${ }^{11}$ Dermatology, \\ ‘Grigore T. Popa' University of Medicine and Pharmacy, 700115 Iasi, Romania
}

Received September 29, 2021; Accepted October 29, 2021

DOI: $10.3892 / \mathrm{etm} .2022 .11184$

\begin{abstract}
Since the introduction of modern phototherapy in 1903 by Nobel Prize-winner Niels Ryberg Finsen, the usage of this therapy in the medical field has grown, techniques have been refined and developed, and it has gained widespread acceptance. Psoriasis vulgaris, parapsoriasis, lichen planus, atopic dermatitis, neonatal jaundice, urticaria, morphea, vitiligo, granuloma annulare and cutaneous $\mathrm{T}$ cell lymphoma are only a few dermatological indications that come along with satisfactory results. Most often, it is a 2nd or 3rd line therapy being an alternative in more severe or refractory diseases. Despite the side effects that may occur after phototherapy, which are often minor, the benefits can be significant. Unfortunately, the absolute contraindications limit the use of this type of treatment and implicitly the management of these patients. The current review aimed to combine the recommendations of phototherapy in dermatology, the types of phototherapy that can be suitable for certain dermatological
\end{abstract}

Correspondence to: Dr Nicoleta Anton, Department of Ophthalmology, 'Grigore T. Popa' University of Medicine and Pharmacy, 16 Universitatii Street, 700115 Iasi, Romania

E-mail: anton.nicoleta1@umfiasi.ro

Dr Diana Stefania Dirzu, Department of Dermatology, Railway Clinical Hospital, 1 Garabet Ibraileanu Street, 700506 Iasi, Romania E-mail: dirzudianastefania@gmail.com

*Contributed equally

Key words: phototherapy, ultraviolet radiation, protocols, side effects, indications diseases and to emphasize its importance in certain conditions that are associated with significant remission rates.

\section{Contents}

1. Introduction

2. Literature review methodology

3. Types of phototherapy

4. Phototherapy protocols

5. Effects of UV radiation

6. Indications for phototherapy in dermatology

7. Side effects and complications

8. Contraindications

9. Conclusions

\section{Introduction}

Heliotherapy has been a therapeutic method used in the treatment of various medical conditions for $>3,500$ years (1). At the beginning of the 20th century, this method was considered to be revolutionary in the treatment of pulmonary tuberculosis, arthritis and small pox, the first dermatological indication being lupus vulgaris (cutaneous tuberculosis) (1). The evolution of modern phototherapy has led to an improved understanding of the ultraviolet (UV) radiation effects. This is a very important aspect to determine which conditions can benefit from this type of treatment. In dermatological maladies, phototherapy must be considered, especially in conditions that do not respond to first-line therapies. Each phototherapy session must be personalized and adapted according to a series of parameters in order to obtain an effective response without any serious side effects. This is possible by following 
the updated protocols (2). Most of the dermatological conditions listed in this review have a significant remission rate after a variable number of phototherapy sessions, which is why this therapeutic method should be taken into consideration more often. The current review aimed to combine the recommendations of phototherapy in dermatology, the types of phototherapy that can be suitable for certain dermatological diseases and to emphasize its importance in certain conditions that are associated with significant remission rates.

\section{Literature review methodology}

The current review aimed to synthesize the recommendations of phototherapy in dermatology, to emphasize its importance in certain conditions that are associated with significant remission rates. PubMed (https://pubmed.ncbi. nlm.nih.gov/), Elsevier (https://www.elsevier.com/en-gb) and Medscape (https://www.medscape.com/pathology) databases were searched, to select the published literature and articles that emerged between 2005 and 2020, using the following combinations of terms: 'phototherapy', 'recommendations', 'psoriasis', 'vitiligo', 'scleroderma', 'atopic dermatitis', 'lichen planus', 'granuloma annulare', 'cutaneous T-cell lymphoma’, 'side effects'. Only clinical trials and reviews, published in English, on human subjects were included. For the theoretical section that explains the basics of phototherapy, the information was extracted from specialized treatises. This review mainly focused on the circumstances in which phototherapy is necessary, which type of phototherapy is more suitable, its benefits, risks and its effectiveness in several selected dermatological pathologies, based on 16 case studies.

\section{Types of phototherapy}

Phototherapy is a useful therapeutic method in the management of a number of dermatological maladies. It uses UV radiation (UVA, UVB) with different wavelengths (2). Depending on the type of radiation and their wavelength, there are several types of phototherapy: i) Narrow Band UVB (NB-UVB); ii) Broadband UVB (BB-UVB); iii) UVA (UVA 1); and iv) Psoralen UVA (PUVA) (2). Among these, PUVA therapy is associated with the highest carcinogenic risk, seven times higher than the rest (2).

\section{Phototherapy protocols}

The phototherapy protocol is different. Thus, in the case of NB-UVB phototherapy, the initial radiation dose is determined according to the minimal erythema dose (MED), starting with 50-70\% of MED, or according to the Fitzpatrick skin phototype. At each session the dose is increased by $10-20 \%, 2$ to 5 sessions per week can be performed (3). In the case of erythema, the dose is decreased, or the treatment is delayed $(3,4)$.

BB-UVB phototherapy follows the same protocol, but the radiation dose is increased by $25 \%$ per session in the first 10 sessions, then it is increased by $10 \%$ per session $(3,4)$.

Psoralen can be administered orally, $0.6 \mathrm{mg} / \mathrm{kg}, 2 \mathrm{~h}$ before irradiation. The initial dose of UVA is determined according to the minimum phototoxic dose (MPD), 50-70\% of the MPD or according to the skin phototype. There can be 2 to 4 sessions per week, in which the dose is increased each week (3). Psoralen can also be given topically. Psoralen baths can be made $(1 \mathrm{mg} / \mathrm{l})$, at a water temperature of $37^{\circ} \mathrm{C}$ for 15 to $20 \mathrm{~min}$, and then UVA exposure is administered. The initial dose of UVA is $30 \%$ of MED, 2 sessions per week can be performed, in which the dose is increased by $20 \%$ per week $(3,4)$.

\section{Effects of UV radiation}

The exerted effects by non-ionizing radiation can guide us on the utility of phototherapy in dermatology. Therefore, UV radiation can cause mast cell apoptosis, collagen degradation, acanthosis and thickening of the stratum corneum (2). It can also stimulate melanogenesis and have an immunosuppressive effect by decreasing the activity of dendritic cells, thus resulting in decreased activation of $\mathrm{T}$ cells (2).

\section{Indications for phototherapy in dermatology}

Given the aforementioned effects, the dermatological disorders from Fitzpatrick's Dermatology by Fitzpatrick and Kang (2) that may benefit from phototherapy are: i) Actinic prurigo; ii) atopic dermatitis; iii) chronic eczema; iv) chronic palmoplantar pustulosis (PPP); v) chronic urticaria; vi) cutaneous T cell lymphoma; vii) granuloma annulare; viii) hydroa vacciniforme (HV); ix) indolent systemic mastocytosis; x) lichen planus; xi) localized and systemic scleroderma; xii) lymphomatoid papulosis; xiii) neonatal jaundice; xiv) parapsoriasis; $\mathrm{xv}$ ) photodermatoses; $\mathrm{xvi}$ ) pityriasis lichenoides; $x v i i)$ pityriasis rubra pilaris (PRP); xviii) primary localized cutaneous amyloidosis (PLCA); xix) psoriasis; $\mathrm{xx}$ ) solar urticaria; xxi) subcorneal pustular dermatosis (SPD; also known as Sneddon-Wilkinson disease); xxii) telangiectasia macularis eruptiva perstans; xxiii) urticaria pigmentosa; and xxiv) vitiligo.

Phototherapy is the primary treatment in neonatal jaundice. Phototherapy is useful for conjugating bilirubin $(5,6)$.

Psoriasis vulgaris is the most common indication for phototherapy (NB-UVB and PUVA being the most widely used applications) (7). Unlike topical therapy, the main advantage of phototherapy is that it can convert psoriasis to skin that is morphologically and histologically normal (7). Usually patients have a good outcome after phototherapy sessions, with long lasting effects (7). UVB therapy is usually combined with one or more topical treatments (corticosteroids, calcipotriene, tazarotene or simply bland emollients) (8). In 1925 the Goeckerman regime was published, which consisted of using coal tar followed by UVB exposure (8). Even after the introduction of novel biological agents in the treatment of psoriasis, the Goeckerman regimen remained a very effective option (9). A number of studies have shown that this regime can induce disease remission in $>80 \%$ of patients (10). NB-UVB phototherapy is usually recommended, and if not available, BB-UVB may be an alternative, but with poorer results (10). Regarding PUVA phototherapy, $>85 \%$ of patients reported remission of symptoms after 20 to 30 sessions (10).

Phototherapy can also be useful in sclerosing skin diseases, especially in localized scleroderma (11). PUVA and UVA 1 are the feasible options in this case, leading to the improvement of 
skin sclerosis, joint mobility, ulcers and histopathology (12-16). UVA 1 phototherapy response rates range between 60 and $100 \%$ after 30 to 40 sessions (17). NB-UVB phototherapy may be an alternative especially in cases with relatively superficial dermal plaques, when PUVA or UVA 1 are not available (17). The protocol is similar to that for psoriasis (18). In a study conducted by Pavlotsky et al (19), on 28 patients, Bath-PUVA phototherapy was associated with complete remission in $39 \%$ of cases, partial remission in $50 \%$ of cases, and the rest did not respond to this type of treatment (19). In a study conducted on 17 patients who underwent between 25 and 35 Bath-PUVA phototherapy sessions, the results were satisfactory, with complete and marked remission of 13 patients in $<3$ months (20). In another study, PUVA cream phototherapy was associated with improved results, but being a study performed on a limited number of patients, we cannot reach a final conclusion (21). Regarding UVA 1 phototherapy, the study performed by Kroft et al (22) on 10 patients, showed significant efficiency, with complete remission on the entire study group after 20 sessions. After a follow-up of 46 weeks, complete remission was maintained for at least 26 weeks (22). Thus, these examples of studies accompanied by positive results indicate the importance of phototherapy in localized scleroderma.

Generalized vitiligo can be treated with PUVA or NB-UVB phototherapy. NB-UVB seems to be the preferable option giving the favorable outcome, as found in several studies $(23,24)$.

Even though the main method of treating lichen planus is topical and systemic corticosteroids, NB-UVB phototherapy has proven to be a good alternative, especially in the disseminated forms $(25,26)$. Also, one study showed that NB-UVB phototherapy may be a promising treatment modality for erosive oral lichen planus (27).

In the early stages of cutaneous $\mathrm{T}$ cell lymphoma, besides topical steroids and nitrogen mustard (28), phototherapy can also be considered, PUVA and NB-UVB being first-line treatments. PUVA phototherapy seems to be associated with much more favorable results (29). A study conducted by Ahmad et al (30) showed the effectiveness of both NB-UVB phototherapy and PUVA phototherapy, registering complete remissions especially in the early stages (IA, IB) of cutaneous $\mathrm{T}$ cell lymphoma in 50 and $64 \%$ of patients, respectively (30).

Furthermore, even in the case of chronic eczema, phototherapy can be an alternative, given the possible anti-inflammatory effect exerted by UV radiation (31).

Atopic dermatitis, also known as atopic eczema, is a common skin condition characterized by chronic inflammation of the skin (32). It can occur at any age (32). Phototherapy is the 2nd line therapy in this condition (33). It may or may not be associated with systemic drugs, especially corticosteroids (33). Studies have shown satisfactory results after performing UVA-1 and NB-UVB phototherapy $(33,34)$. NB-UVB causes the destruction of $T$ cells in the epidermis and inhibits the release of cytokines and the activity of $\mathrm{T}$ helper (Th)1 lymphocytes (which in chronic atopic dermatitis are hyperstimulated) leading to a Th2 response (34). UVB radiation penetrates only the epidermis, so the phototherapy effect is superficial, which is suitable for chronic atopic dermatitis (34). Since UVA radiation penetrates deep into the dermis, this form of therapy is suitable for acute atopic dermatitis (35).
In a previous study conducted by Dayal et al (36) on a group of 30 children, a considerable remission rate was registered after 6, 12, 18 and 24 NB-UVB phototherapy sessions, and the results were maintained for at least 2 years (36). Another study conducted by Tintle et al (37), on 12 adult patients with moderate to severe atopic dermatitis showed a remission rate of at least $50 \%$ after a variable number of NB-UVB phototherapy sessions, no more than 23 . According to another study performed on a group of 32 patients with acute exacerbated atopic dermatitis, UVA 1 phototherapy gave very good results, but after 3 months, the skin condition had reached the pretreatment level (38). Therefore, it can be concluded that NB-UVB phototherapy is feasible for chronic atopic dermatitis, which is accompanied by long-term results, and UVA 1 phototherapy has implications in acute atopic dermatitis, unfortunately with short term results.

Granuloma annulare is a fairly rare, benign and asymptomatic inflammatory skin condition of unknown etiology, frequently associated with diabetes mellitus (2). There are multiple forms of treatment, including topical and systemic steroids, dapsone, cyclosporine, systemic retinoids, phototherapy and rifampicin, ofloxacin and minocycline therapy (39). The case presented by Muylaert et al (40) highlights the efficiency of NB-UVB phototherapy in disseminated annular granuloma, refractory to other therapies. Along with this case, other studies were carried out and reached the same conclusion (41-43).

PPP is a rare chronic recurrent disease of unknown etiology characterized by the appearance of sterile blisters on the palms of the hands and/or soles of the feet (2). In addition to corticosteroids, PUVA and NB-UVB may be considered for the treatment of this condition, NB-UVB being preferred given the lower risk of secondary skin cancer development (44).

Another rare disease of unknown etiology is pityriasis lichenoides. This is characterized by the appearance of small, scaly papules $(45,46)$. The treatment of this dermatosis consists of corticosteroids, oral antibiotics and phototherapy, which is primarily used in the recurrent and resistant cases of the disease $(47,48)$. A study conducted by Fernández-Guarino et al (49), performed on eight patients undergoing an average of $23 \mathrm{NB}-\mathrm{UVB}$ sessions resulted in a complete remission rate of $88 \%$, but the relapse rate was $43 \%$ in the first 6 months. Phototherapy may also be useful in children, but the most common indications among these patients are psoriasis and atopic dermatitis (50).

PRP is clinically characterized by follicular keratotic plugs, red to orange plaques and palmoplantar hyperkeratosis (2). NB-UVB can be a very effective therapy in this case as well (51).

Lymphomatoid papulosis is a chronic papulonecrotic or papulonodular skin disease and a rare form of indolent cutaneous $\mathrm{T}$ cell lymphoma characterized by crops of recurrent self-healing papules (2). PUVA-Bath photochemotherapy is associated with satisfactory results and along with topical corticosteroid therapy and methotrexate, are among the first-line therapies for this disease (52-54).

PLCA is the deposition of amyloid in an apparently normal skin without affecting the internal organs (2). A variety of treatment options for PLCA have been reported, including retinoids, corticosteroids, cyclophosphamide, cyclosporine, amitriptyline, colchicine, catharanthine, tacrolimus, dimethyl sulfoxide, vitamin $\mathrm{D}_{3}$ analogs, capsaicin, menthol, hydrocolloid 
dressings, surgical modalities, laser treatment and among phototherapy types, NB-UVB is considered to be very useful for prurigo $(55,56)$.

Studies have shown the short-term efficacy of NB-UVB in the treatment of parapsoriasis $(57,58)$.

$\mathrm{HV}$ is a rare, chronic photodermatosis of unknown origin that can occur in childhood (2). It is frequently associated with Epstein-Barr infection (2). Among oral antimalarials, such as hydroxychloroquine, and oral antioxidants, such as $\beta$-carotene, phototherapy NB-UVB or PUVA may be considered $(59,60)$.

$\mathrm{SPD}$ is a rare neutrophilic dermatosis with a largely unknown etiology. PUVA, BB-UVB and NB-UVB alone or in combination with dapsone and/or retinoids can be efficient (61-63).

Scleredema is a rare form of disease characterized by excessive mucin deposits among the collagen fibers in the dermis, which determines the skin induration (64-67). Among the therapies used in this condition (systemic steroids, cyclosporine, methotrexate, high-dose penicillin, penicillamine, electron beam, and glycemic control with prostaglandin E1), UVA, PUVA and NB-UVB may be associated with good results, but most authors prefer UVA and PUVA for this condition as UVA radiation penetrates more deeply into the dermis, while UVB radiation reaches the epidermis and the upper dermis (68-76).

\section{Side effects and complications}

Phototherapy is associated with a series of side effects. Short-term side effects include: i) Erythema; ii) xerosis; iii) pruritus; iv) skin hyperpigmentation; v) blistering; vi worsening skin disease; and v) photoconjunctivitis or photokeratitis (eye protection is mandatory). The long-term side effects include: i) Photoaging, such as wrinkling, freckling, xerosis, telangiectasia, elastosis and atrophy; and ii) photocarcinogenesis, such as actinic keratoses, squamous cell carcinoma, basal cell carcinoma, melanoma, genital skin cancer [the risk of which is very high (x286), especially after PUVA phototherapy, which is why shields are mandatory] and cataracts (77).

\section{Contraindications}

The contraindications for phototherapy, according to Coelho and Apetato (77) and Krutmann et al (78), are as follows: i) Systemic diseases with a photosensitive component, such as systemic lupus erythematosus or dermatomyositis; ii) photodermatoses, such as xeroderma pigmentosum and basal cell nevus syndrome; iii) Fitzpatrick skin type 1 and 2 (PUVA phototherapy); iv) past excessive exposure to natural sun light or phototherapy; v) immunosuppressive medication; vi) photosensitizing creams or medication; vii) past skin cancer, especially melanoma; viii) pregnancy and breastfeeding (PUVA); ix) immobility or inability to stand unassisted for $\geq 10 \mathrm{~min}$; and $\mathrm{x}$ ) congenital erythropoietic porphyria, or a family history of porphyria.

\section{Conclusions}

Overall, phototherapy is a useful therapeutic method in the management of numerous dermatological maladies and lately it is starting to gain widespread acceptance. The studied articles demonstrated that NB-UVB seems to be the best alternative for psoriasis vulgaris, vitiligo, lichen planus, chronic eczema and annular granuloma, while PUVA phototherapy is useful for localized scleroderma (UVA 1 sessions can also be performed), psoriasis vulgaris (the remission rate is similar to the rate after NB-UVB phototherapy), vitiligo (NB-UVB is preferred), cutaneous $\mathrm{T}$ cell lymphoma (another alternative is NB-UVB, but it is associated with poorer results) and acute atopic dermatitis. As long as the protocols and treatment guidelines are followed, favorable results should be obtained and the potential risk of side effects will be minimized. Most of the dermatological conditions listed above have a significant remission rate after a variable number of phototherapy sessions, which is why this therapeutic method should be taken into consideration more often.

\section{Acknowledgements}

Not applicable.

\section{Funding}

Publishing funds were supported by the Association of Dermatologists from Moldova.

\section{Availability of data and materials}

Not applicable.

\section{Authors' contributions}

DEB, DCB and MPT contributed to the study design, participated in the entire review process and prepared the manuscript. DSD, DCB, ACN and IB contributed to collecting the relevant literature and critical interpretation. ACN, IB, CMB, GB, AD, NA and EAP conceived the concept of the review and modified the manuscript. All authors have read and approved the final manuscript. Data authentication is not applicable.

\section{Ethics approval and consent to participate}

Not applicable.

\section{Patient consent for publication}

Not applicable.

\section{Competing interests}

The authors declare that they have no competing interests.

\section{References}

1. Hönigsmann H: History of phototherapy in dermatology. Photochem Photobiol Sci 12: 16-21, 2013.

2. Fitzpatrick TB and Kang S: Fitzpatrick's Dermatology.9th edition. McGraw-Hill Education, New York, NY, pp3635-3664, 2019.

3. Menter A, Korman NJ, Elmets CA, Feldman SR, Gelfand JM, Gordon KB, Gottlieb A, Koo JYM, Lebwohl M, Lim HW, et al: Guidelines of care for the management of psoriasis and psoriatic arthritis: Section 5. Guidelines of care for the treatment of psoriasis with phototherapy and photochemotherapy. J Am Acad Dermatol 62: 114-135, 2010. 
4. Krutmann J, Hönigsmann $\mathrm{H}$ and Elmets C: Dermatological Phototherapy and Photodiagnostic Methods. 2nd edition. Springer-Verlag, Berlin, pp30-35, 2009.

5. Woodgate P and Jardine LA: Neonatal jaundice: Phototherapy. BMJ Clin Evid 22: 0319, 2015.

6. Mreihil K, Madsen P, Nakstad B, Benth JS, Ebbesen F and Hansen TW: Early formation of bilirubin isomers during phototherapy for neonatal jaundice: Effects of single vs. double fluorescent lamps vs. photodiodes. Pediatr Res 78: 56-62, 2015.

7. Morison and Warwick L: Phototherapy and Photochemotherapy of Skin Disease. Taylor \& Francis Group, Baltimore, MD, pp30-33, 2005

8. Menter A and Cram DL: The goeckerman regimen in two psoriasis day care centers. J Am Acad Dermatol 9: 59-65, 1983.

9. Gupta R, Debbaneh M, Butler D, Huynh M, Levin E, Leon A, Koo J and Liao W: The goeckerman regimen for the treatment of moderate to severe psoriasis. J Vis Exp 77: 50509, 2013.

10. Torres AE, Lyons AB, Hamzavi IH and Lim HW: Role of phototherapy in the era of biologics. J Am Acad Dermatol 84 479-485, 2021

11. Fett NM: Morphea: Evidence-based recommendations for treatment. Indian J Dermatol Venereol Leprol 78: 135-141, 2012.

12. Chaowattanapanit S, Choonhakarn C, Foocharoen C and Julanon N: Phototherapy in systemic sclerosis: Review. Photodermatol Photoimmunol Photomed 33: 296-305, 2017.

13. El-Mofty M, Mostafa W, El-Darouty M, Bosseila M, Nada H, Yousef R, Esmat S, El-Lawindy M, Assaf M and El-Enani G: Different low doses of broad-band UVA in the treatment of morphea and systemic sclerosis. Photodermatol Photoimmunol Photomed 20: 148-156, 2004.

14. Usmani N, Murphy A, Veale D, Goulden V and Goodfield M: Photochemotherapy for localized morphoea: Effect on clinical and molecular markers. Clin Exp Dermatol 33: 698-704, 2008.

15. Ozdemir M, Engin B, Toy $\mathrm{H}$ and Mevlitoglu I: Treatment of plaque-type localized scleroderma with retinoic acid and ultraviolet A plus the photosensitizer psoralen: A case series. J Eur Acad Dermatol Venereol 22: 519-521, 2008.

16. Kreuter A, Gambichler T, Avermaete A, Jansen $\mathrm{T}$, Hoffmann M, Hoffmann K, Altmeyer P, von Kobyletzki G and Bacharach-Buhles M: Combined treatment with calcipotriol ointment and low-dose ultraviolet A1 phototherapy in childhood morphea. Pediatr Dermatol 18: 241-225, 2001.

17. Kreuter A, Hyun J, Stücker M, Sommer A, Altmeyer P and Gambichler T: A randomized controlled study of low-dose UVA1, medium-dose UVA1, and narrowband UVB phototherapy in the treatment of localized scleroderma. J Am Acad Dermatol 54 440-447, 2006

18. Sator PG, Radakovic S, Schulmeister K, Hönigsmann H and Tanew A: Medium-dose is more effective than low-dose ultraviolet A1 phototherapy for localized scleroderma as shown by $20-\mathrm{MHz}$ ultrasound assessment. J Am Acad Dermatol 60 : 786-791, 2009.

19. Pavlotsky F, Sakka N, Lozinski A and Barzilai A: Bath psoralen-UVA photochemotherapy for localized scleroderma: Experience from a single institute. Photodermatol Photoimmunol Photomed 29: 247-252, 2013.

20. Kerscher M, Meurer M, Sander C, Volkenandt M, Lehmann P, Plewig G and Röcken M: PUVA bath photochemotherapy for localized scleroderma. Evaluation of 17 consecutive patients Arch Dermatol 132: 1280-1282, 1996

21. Grundmann-Kollmann M, Ochsendorf F, Zollner TM, Spieth K, Sachsenberg-Studer E, Kaufmann R and Podda M: PUVA-cream photochemotherapy for the treatment of localized scleroderma. J Am Acad Dermatol 43: 675-678, 2000.

22. Kroft EB, van de Kerkhof PC, Gerritsen MJ and de Jong EM Period of remission after treatment with UVA-1 in sclerodermic skin diseases. J Eur Acad Dermatol Venereol 22: 839-844, 2008

23. Bae JM, Jung HM, Hong BY, Lee JH, Choi WJ, Lee JH and Kim GM: Phototherapy for vitiligo: A systematic review and meta-analysis. JAMA Dermatol 153: 666-674, 2017.

24. Bhatnagar A, Kanwar AJ, Parsad D and De D: Psoralen and ultraviolet A and narrow-band ultraviolet B in inducing stability in vitiligo, assessed by vitiligo disease activity score: An open prospective comparative study. J Eur Acad Dermatol Venereol 21: $1381-1385,2007$.

25. Habib F, Stoebner PE, Picot E, Peyron JL, Meynadier J and Meunier L: Narrow band UVB phototherapy in the treatment of widespread lichen planus. Ann Dermatol Venereol 132: 17-20, 2005 (In French).
26. Puza $\mathrm{C}$ and Cardones AR: Concepts and controversies in the treatment of cutaneous lichen planus. G Ital Dermatol Venereol 152: 607-614, 2017.

27. Kassem R, Yarom N, Scope A, Babaev M, Trau H and Pavlotzky F: Treatment of erosive oral lichen planus with local ultraviolet B phototherapy. J Am Acad Dermatol 66: 761-766, 2012.

28. Mehta-Shah N, Horwitz SM, Ansell S, Ai WZ, Barnes J, Barta SK, Clemens MW, Dogan A, Fisher K, Goodman AM, et al: NCCN guidelines insights: Primary cutaneous lymphomas, version 2.2020. J Natl Compr Canc Netw 18: 522-536, 2020.

29. Marka A and Carter JB: Phototherapy for cutaneous T-cell lymphoma. Dermatol Clin 38: 127-135, 2020.

30. Ahmad K, Rogers S, McNicholas PD and Collins P: Narrowband UVB and PUVA in the treatment of mycosis fungoides: A retrospective study. Acta Derm Venereol 87: 413-417, 2007.

31. Patrizi A, Raone B and Ravaioli GM: Safety and efficacy of phototherapy in the management of eczema. Adv Exp Med Biol 996: 319-331, 2017.

32. Bieber T: Atopic dermatitis. Ann Dermatol 22: 125-137, 2010

33. Garritsen FM, Brouwer MWD, Limpens J and Spuls PI: Photo(chemo) therapy in the management of atopic dermatitis: An updated systematic review with implications for practice and research. Br J Dermatol 170: 501-513, 2014.

34. Grundmann SA and Beissert S: Modern aspects of phototherapy for atopic dermatitis. J Allergy (Cairo) 2012: 121797, 2012.

35. Zandi S, Kalia S and Lui H: UVA1 phototherapy: A concise and practical review. Skin Therapy Lett 17: 1-4, 2012

36. Dayal S, Pathak K, Sahu P and Jain VK: Narrowband UV-B phototherapy in childhood atopic dermatitis: Efficacy and safety. An Bras Dermatol 92: 801-806, 2017.

37. Tintle S, Shemer A, Suárez-Fariñas M, Fujita H, Gilleaudeau $P$, Sullivan-Whalen M, Johnson-Huang L, Chiricozzi A, Cardinale I, Duan S, et al: Reversal of atopic dermatitis with narrow-band UVB phototherapy and biomarkers for therapeutic response. J Allergy Clin Immunol 128: 583-593, 2011

38. Abeck D, Schmidt T, Fesq H, Strom K, Mempel M, Brockow K and Ring J: Long-term efficacy of medium-dose UVA1 phototherapy in atopic dermatitis. J Am Acad Dermatol 42: 254-257, 2000.

39. Lukács J, Schliemann S and Elsner P: Treatment of generalized granuloma annulare-a systematic review. J Eur Acad Dermatol Venereol 29: 1467-1480, 2015.

40. Muylaert BP, Almada R and de Vasconcelos RC: Granuloma annulare treated with narrowband UVB phototherapy. An Bras Dermatol 92 (Suppl 5): S82-S84, 2017

41. Inui S, Nishida Y, Itami S and Katayama I: Disseminated granuloma annulare responsive to narrowband ultraviolet B therapy. J Am Acad Dermatol 53: 533-534, 2005.

42. Solano-López G, Concha-Garzón MJ, de Argila D and Daudén E: Successful treatment of disseminated granuloma annulare with narrowband UV-B phototherapy. Actas Dermosifiliogr 106: 240-241, 2015 (In English, Spanish).

43. Pavlovsky M, Samuelov L, Sprecher E and Matz H: NB-UVB phototherapy for generalized granuloma annulare. Dermatol Ther 29: 152-154, 2016

44. Saurat JH, Lachapelle JM and Lipsker D: Dermatologie et Infections Sexuellement Transmissibles, 5th edition. Elsevier Masson, Paris, 2009.

45. Clarey DD, Lauer SR and Trowbridge RM: Clinical, dermatoscopic, and histological findings in a diagnosis of pityriasis lichenoides. Cureus 20: e8725, 2020 .

46. Reichel A, Grothaus J and Ott H: Pityriasis lichenoides acuta (PLEVA) pemphigoides: A rare bullous variant of PLEVA. Pediatr Dermatol 37: 710-712, 2020.

47. Aydogan K, Saricaoglu H and Turan H: Narrowband UVB (311 nm, TL01) phototherapy for pityriasis lichenoides. Photodermatol Photoimmunol Photomed 24: 128-133, 2008.

48. Jung F, Sibbald C, Bohdanowicz M, Ingram JR and Piguet V: Systematic review of the efficacies and adverse effects of treatments for pityriasis lichenoides. Br J Dermatol 183: 1026-1032, 2020.

49. Fernández-Guarino M, Aboin-Gonzalez S, Blanco CC, Tarjuelo DV and Ochayta PL: Treatment of adult diffuse pityriasis lichenoides chronica with narrowband ultraviolet B: Experience and literature review. Clin Exp Dermatol 42: 303-305, 2017.

50. Eustace K, Dolman S, Alsharqi A, Sharpe G and Parslew R: Use of phototherapy in children. Pediatr Dermatol 34: 150-155, 2017.

51. Vergilis-Kalner IJ, Mann DJ, Wasserman J, Petronic-Rosic V and Toukas MM: Pityriasis rubra pilaris sensitive to narrow bandultraviolet B light therapy. J Drugs Dermatol 8: 270-273, 2009. 
52. Hoetzenecker W, Guenova E, Hoetzenecker K, Yazdi A, Röcken M and Berneburg M: Successful treatment of recalcitrant lymphomatoid papulosis in a child with PUVA-bath photochemotherapy. Eur J Dermatol 19: 646-647, 2009.

53. Snider S, Costello CM, Ederaine S, Besch-Stokes J, Severson KJ, DiCaudo DJ, Pittelkow MR and Mangold AR: A case of pediatric lymphomatoid papulosis treated with photodynamic therapy and narrowband ultraviolet B. Pediatr Dermatol 37: 881-883, 2020

54. Rodrigues M, McCormack C, Yap LM, Prince HM, Roberts H Williams R and Foley P: Successful treatment of lymphomatoid papulosis with photodynamic therapy. Australas J Dermatol 50 129-132, 2009.

55. Weidner T, Illing $\mathrm{T}$ and Elsner P: Primary localized cutaneous amyloidosis: A systematic treatment review. Am J Clin Dermatol 18: 629-642, 2017.

56. Hudson LD: Macular amyloidosis: Treatment with ultraviolet B. Cutis 38: 61-62, 1986.

57. Herzinger T, Degitz K, Plewig G and Röcken M: Treatment of small plaque parapsoriasis with narrow-band $(311 \mathrm{~nm})$ ultraviolet B: A retrospective study. Clin Exp Dermatol 30: 379-381, 2005.

58. Hofer A, Cerroni L, Kerl H and Wolf P: Narrowband (311-nm) UV-B therapy for small plaque parapsoriasis and early-stage mycosis fungoides. Arch Dermatol 135: 1377-1380, 1999.

59. Collins P and Ferguson J: Narrow-band UVB (TL-01) phototherapy: An effective preventative treatment for the photodermatoses. Br J Dermatol 132: 956-963, 1995.

60. Hashizume H, Tokura Y, Oku T, Iwamoto Y and Takigawa $\mathrm{M}$ : Photodynamic DNA-breaking activity of serum from patients with various photosensitivity dermatoses. Arch Dermatol Res 287: 586-590, 1995

61. Bauwens M, De Coninck A and Roseeuw D: Subcorneal pustular dermatosis treated with PUVA therapy. A case report and review of the literature. Dermatology 198: 203-205, 1999.

62. Orton DI and George SA: Subcorneal pustular dermatosis responsive to narrowband (TL-01) UVB phototherapy. Br JDermatol 137: 149-161, 1997.

63. Marliere V, Beylot-Barry M, Beylot C and Doutre M: Successful treatment of subcorneal pustular dermatosis (Sneddon-wilkinson disease) by acitretin: Report of a case. Dermatology 199: 153-155, 1999.

64. Knobler R, Moinzadeh P, Hunzelmann N, Kreuter A, Cozzio A, Mouthon L, Cutolo M, Rongioletti F, Denton CP, Rudnicka L, et al: European dermatology forum S1-guideline on the diagnosis and treatment of sclerosing diseases of the skin, part 1: Localized scleroderma, systemic sclerosis and overlap syndromes. J Eur Acad Dermatol Venereol 31: 1401-1424, 2017.

65. Martín C, Requena L, Manrique K, Manzarbeitia FD and Rovira A: Scleredema diabeticorum in a patient with type 2 diabetes mellitus. Case Rep Endocrinol 2011: 560273, 2011.
66. Shazzad MN, Azad AK, Abdal SJ, Afrose R, Rahman MM and Haq SA: Scleredema diabeticorum-A case report. Mymensingh Med J 24: 606-609, 2015.

67. Cole GW, Headley J and Skowsky R: Scleredema diabeticorum: A common and distinct cutaneous manifestation of diabetes mellitus. Diabetes Care 6: 189-192, 1983.

68. Rongioletti F, Kaiser F, Cinotti E, Metze D, Battistella M, Calzavara-Pinton PG, Damevska K, Girolomoni G, André J, Perrot JL, et al: Scleredema. A multicentre study of characteristics, comorbidities, course and therapy in 44 patients. J Eur Acad Dermatol Venereol 29: 2399-2404, 2015.

69. Thumpimukvatana N, Wongpraparut C and Lim HW: Scleredema diabeticorum successfully treated with ultraviolet A1 phototherapy. J Dermatol 37: 1036-1039, 2010.

70. Kroft EB, Berkhof NJ, van de Kerkhof PC, Gerritsen RM and de Jong EM: Ultraviolet A phototherapy for sclerotic skin diseases: A systematic review. J Am Acad Dermatol 59: 1017-1030, 2008.

71. Xiao T, Yang ZH, He CD and Chen HD: Scleredema adultorum treated with narrow-band ultraviolet B phototherapy. J Dermatol 34: 270-272, 2007.

72. Yoshimura J, Asano Y, Takahashi T, Uwajima Y, Kagami S, Honda H, Idezuki T, Igarashi A and Sato S: A case of scleredema adultorum successfully treated with narrow-band ultraviolet B phototherapy. Mod Rheumatol 26: 302-306, 2016.

73. Grundmann-Kollmann M, Ochsendorf F, Zollner TM, Spieth K, Kaufmann R and Podda M: Cream PUVA therapy for scleredema adultorum. Br J Dermatol 142: 1058-1059, 2000.

74. Hager CM, Sobhi HA, Hunzelmann N, Wickenhauser C, Scharenberg R, Krieg $\mathrm{T}$ and Scharffetter-Kochanek K: Bath-PUVA therapy in three patients with scleredema adultorum. J Am Acad Dermatol 38: 240-242, 1998.

75. Yüksek J, Sezer E, Köseoglu D, Markoç F and Yildiz H: Scleredema treated with broad-band ultraviolet A phototherapy plus colchicine. Photodermatol Photoimmunol Photomed 26: 257-260, 2010

76. Kokpol C, Rajatanavin N and Rattanakemakorn P: Successful treatment of scleredema diabeticorum by combining local PUVA and colchicine: A case report. Case Rep Dermatol 4: 265-268, 2012.

77. Coelho MM and Apetato M: The dark side of the light: Phototherapy adverse effects. Clin Dermatol 34: 556-562, 2016.

78. Krutmann J,Honigsmann H and Elmets CA (eds): Dermatological phototherapy and photodiagnostic methods. Springer-Verlag, Berlin, 2009.

c) () $\Theta$ This work is licensed under a Creative Commons Attribution-NonCommercial-NoDerivatives 4.0 International (CC BY-NC-ND 4.0) License. 